\title{
Hormonal responses and clinical outcome are the same with three doses of gonadotropin-releasing hormone agonist used in the short stimulation protocol
}

\author{
Abdulmagid Sarhan ${ }^{1}$, Sherine Elshazly ${ }^{1}$, Mervat Harira ${ }^{1}$
}

${ }^{1}$ Zagazig University, Egypt

\begin{abstract}
Objective: The aim of this study was to compare 3 different doses of GnRH-a in a short protocol on ICSI outcome. Methods: 91 ovulatory patients were randomly assigned to three groups; group $A(N=34)$, group $B(N=34)$ and group $\mathrm{C}(\mathrm{N}=23)$. All started treatment with urinary gonadotropins, 2 ampoules per day and GnRH-a (Triptorelin) on the first day of the menstrual period and continued till the day of (hCG) administration. The daily dose of Triptorelin was $0.1 \mathrm{mg}, 50 \mu \mathrm{g}$, and $25 \mu \mathrm{g}$ in groups $\mathrm{A}, \mathrm{B}$ and $\mathrm{C}$ respectively.

Results: Stimulation requirements, days of stimulation and total ampoules of gonadotropins did not differ between the three groups. The mean number of follicles aspirated and the mean number of Metaphase 2 oocytes retrieved were similar in the three groups. Fertilization and cleavage rates were similar in the three groups. The mean number of embryos available for transfer was $6.4 \pm 0.5,9.4 \pm 0.5$ and $7 \pm 0.7$ in groups $A, B$ and $C$, with a significant difference only between groups $A$ and $B$. Pregnancy rates per cycle were $35.3 \%, 35.3 \%$ and $34.8 \%$ for groups A, B and $\mathrm{C}$, respectively with no significant difference.

Conclusion: Early and late hormonal changes, stimulation requirements and final outcome were similar with the different doses of the agonist. Other factors should be considered, most importantly: treatment cost and side effects.
\end{abstract}

Keywords: Gonadotropin-releasing hormone agonist, ICSI clinical outcome, pregnancy rate

\section{INTRODUCTION}

Controlled ovarian stimulation for assisted reproduction uses gonadotropin releasing hormone agonist ( $\mathrm{GnRH}-\mathrm{a}$ ) routinely either in its short (flare-up) or long protocol (Orvieto et al., 2002). Many studies have been investigating the optimal dose of GnRH-a since the early 1980s (Tolis et al., 1982; Monroe et al., 2006). The routine daily dose of the different agonists used was introduced by trials and is still not uniformly established (Lenton \& Mohamed, 2005). Reduced daily dose of GnRH-a has been suggested by several authors (Ben-Rafael et al., 2000; Janssens et al., 2000).

Among the advantages of reducing the dose of the agonist are: decreasing cost and side effects of the medications, decreasing the amount of gonadotropins used for stimulation with its costs and the possible occurrence of ovarian hyperstimulation. We have to weigh these advantages against the possible insufficiency of a smaller dose to maintain pituitary gland suppression and to prevent the occurrence of spontaneous LH surge leading to cycle cancellation. LH surges occur in $20 \%$ of IVF patients leading to interruption of the IVF cycles, as shown in placebo-controlled studies involving GnRH agonists (Janssens et al., 2000; Edwards et al., 1996). It is well established that the prevention of spontaneous LH surge is the main function of a GnRH agonist and the main reason for improved IVF outcome associated with its use (Broekmans et al., 1996).
The objective of this prospective randomized controlled study was to characterize the daily changes in the levels of luteinizing hormone ( $\mathrm{LH})$ and estradiol $\left(\mathrm{E}_{2}\right)$ and to compare intracytoplasmic sperm injection (ICSI) outcomes from 3 different doses of GnRH-a (Triptorelin, $0.1 \mathrm{mg}, 50 \mu \mathrm{g}$, and $25 \mu \mathrm{g}$ ) used in a short GnRH agonist protocol for normal ovulatory females.

\section{MATERIALS AND METHODS}

Ninety-one patients were randomly assigned to one of three groups: group A (34 patients), group B (34 patients) and Group C (23 patients).

All the patients started treatment with the short GnRH agonist stimulation protocol (flare-up) where urinary gonadotropins, and $\mathrm{GnRH}-\mathrm{a}$ were started on the first day of the menstrual cycle or induced withdrawal bleeding and continued till the day of human chorionic gonadotropins (hCG) administration. The daily dose of Triptorelin (Decapepty, Ferring, Sweden) was $0.1 \mathrm{mg}, 50 \mu \mathrm{g}$, and $25 \mu \mathrm{g}$ in groups $A, B$ and $C$ respectively. Stimulation was performed using human menopausal gonadotropin (Merional, IBSA, Italy) or purified urinary FSH (Fostimon, IBSA, Italy) starting at a daily dose of 2 ampoules and adjusted according to ovarian response. Ovarian response was monitored frequently by trans-vaginal ultrasonography. When there were two or more follicles with a mean diameter of $>17 \mathrm{~mm}$ and serum estradiol $\left(E_{2}\right)$ level of $\geq 200 \mathrm{Pg} / \mathrm{ml}$ per mature follicle, we administered 10,000 IU of hCG (Choriomon, IBSA, Italy).

Trans-vaginal oocyte retrieval was performed $35 \mathrm{~h}$ after hCG injection. Intra-cytoplasmic Sperm injection (ICSI) was performed on metaphase II oocytes according to the conventional protocol. Embryo transfer was performed vaginally under abdominal ultrasound guidance on the second or third day after retrieval. Up to four embryos were transferred. The luteal phase support was started on the day of embryo transfer by either vaginal progesterone 400 mg (Cyclogest, Actavis Barnstaple EX32, UK) or intramuscular progesterone $100 \mathrm{mg}$ (Prontogest, EIPCO, Egypt) according to patient preference.

Clinical pregnancy was defined by the presence of intrauterine gestational $\operatorname{sac}(\mathrm{s})$ with pulsating heart beats on trans-vaginal ultrasound scan at 5-6 weeks' gestation with increasing serum B-hCG levels.

Serum levels of $\mathrm{LH}$ and $\mathrm{E}_{2}$ were measured daily with commercially available enzyme immunoassay kits (Cobas, Elecsys, Enzymun, Roche diagnostics GmbH, Sandhofer Strasse116, Germany).

Statistical analysis:

The demographic data of the patients, hormonal levels, stimulation requirements and outcome variables were compared for the three groups. Results are presented as mean \pm standard deviation. Where appropriate, $x 2$ test and t-test were used for analysis, using SPSS for Windows version 11.0 (SPSS Inc., Chicago, IL USA). $P<05$ was considered statistically significant. 


\section{RESULTS}

The mean age of the patients $(34.6 \pm 3.2,34.6 \pm 3.8$ and $35 \pm 4.1$ years), and the mean duration of infertility $(7.4 \pm 0.8,6.6 \pm 0.6$ and $7.7 \pm 0.7$ years), did not differ between the three groups. The distribution of the different causes of infertility was similar in the three groups. The basal levels of $\mathrm{LH}(3.8 \pm 0.4 \mathrm{mIU} / \mathrm{ml}, 3.6 \pm 0.3 \mathrm{mIU} /$ $\mathrm{ml}$ and $3.7 \pm 0.4 \mathrm{mIU} / \mathrm{ml})$ and that of $\mathrm{E}_{2}(49 \pm 3.1 \mathrm{Pg} / \mathrm{ml}$, $49 \pm 3 \mathrm{Pg} / \mathrm{m}$ and $55 \pm 6 \mathrm{Pg} / \mathrm{ml}$ ) were similar in the 3 groups (table 1).

Early changes in LH levels:

The basal levels of LH $(3.8 \pm 0.4 \mathrm{mIU} / \mathrm{ml}, 3.6 \pm 0.3 \mathrm{mIU} /$ $\mathrm{ml}$ and $3.7 \pm 0.4 \mathrm{mIU} / \mathrm{ml}$ ) were similar in the 3 groups. 24 hours after treatment onset, the level of LH rose markedly to 4-5 times the basal levels in the three study groups with a mean of $22 \pm 2.3 \mathrm{mIU} / \mathrm{ml}, 19 \pm 1.5 \mathrm{mIU} / \mathrm{ml}$ and $21 \pm 2.5$ $\mathrm{mIU} / \mathrm{ml}$ in groups $\mathrm{A}, \mathrm{B}$ and $\mathrm{C}$ respectively. The level of LH dropped on the third day to a mean value of $13.3 \pm 2.6$ $\mathrm{mIU} / \mathrm{ml}, 9 \pm 0.8 \mathrm{mIU} / \mathrm{ml}$ and $9 \pm 1 \mathrm{mIU} / \mathrm{ml}$ and continued to decrease on the fourth and fifth days. The level of LH on days 3 and 4 were significantly higher in group $A$ than the other 2 groups (Table 2, Figure 1)

Early Changes in $\mathrm{E}_{\mathbf{2}}$ level:

The basal levels of $\mathrm{E}_{2}(49 \pm 3.1 \mathrm{Pg} / \mathrm{ml}, 49 \pm 3 \mathrm{Pg} / \mathrm{ml}$ and

Table 1. demographic data of study groups

\begin{tabular}{|c|c|c|c|c|}
\hline Group & \multirow{2}{*}{$\begin{array}{l}\text { Group A } \\
(N=34)\end{array}$} & \multirow{2}{*}{$\begin{array}{l}\text { Group B } \\
(N=34)\end{array}$} & \multirow{2}{*}{$\begin{array}{l}\text { Group C } \\
(N=23)\end{array}$} & \multirow[t]{2}{*}{ P Value } \\
\hline Demographic Data & & & & \\
\hline Age (years) & $34.6 \pm 3.2$ & $34.6 \pm 3.8$ & $35 \pm 4.1$ & NS \\
\hline Duration of infertility (years) & $7.4 \pm 0.8$ & $6.6 \pm 0.6$ & $7.7 \pm 0.7$ & NS \\
\hline Tubal factor infertility & $14(41.2 \%)$ & $13(38.2 \%)$ & $9(39 \%)$ & NS \\
\hline Male factor Infertility & $15(44.1 \%)$ & $17(50 \%)$ & $11(48 \%)$ & NS \\
\hline Unexplained Infertility & $5(14.7 \%)$ & $4(11.8 \%)$ & $3(13 \%)$ & NS \\
\hline Basal LH (mIU/ml) & $3.8 \pm 0.4$ & $3.6 \pm 0.3$ & $3.7 \pm 0.4$ & NS \\
\hline Basal $E_{2}(P g / m l)$ & $49 \pm 3.1$ & $49 \pm 3$ & $55 \pm 6$ & NS \\
\hline
\end{tabular}

Table 2. Early changes in LH levels

\begin{tabular}{|c|c|c|c|c|}
\hline Group & \multirow{2}{*}{$\begin{array}{c}\text { Group A } \\
(N=34)\end{array}$} & \multirow{2}{*}{$\begin{array}{c}\text { Group B } \\
(N=34)\end{array}$} & \multirow{2}{*}{$\begin{array}{l}\text { Group C } \\
(N=23)\end{array}$} & \multirow[t]{2}{*}{ P Value } \\
\hline LH level (mIU/ml) & & & & \\
\hline Basal LH & $3.8 \pm 0.4$ & $3.6 \pm 0.3$ & $3.7 \pm 0.4$ & NS \\
\hline Day 2 LH & $22 \pm 2.3$ & $19 \pm 1.5$ & $21 \pm 2.5$ & NS \\
\hline Day 3 LH & $13.3 \pm 2.6 * *$ & $9 \pm 0.8 *$ & $9 \pm 1 *$ & $<0.05$ \\
\hline Day 4 LH & $9.9 \pm 1.6 * *$ & $6.8 \pm 0.6 *$ & $6.2 \pm 0.7^{*}$ & $<0.05$ \\
\hline Day 5 LH & $7.2 \pm 1.3$ & $5.4 \pm 0.4$ & $4.8 \pm 0.8$ & NS \\
\hline
\end{tabular}

Figure 1. Early changes in $\mathrm{KH}$ level

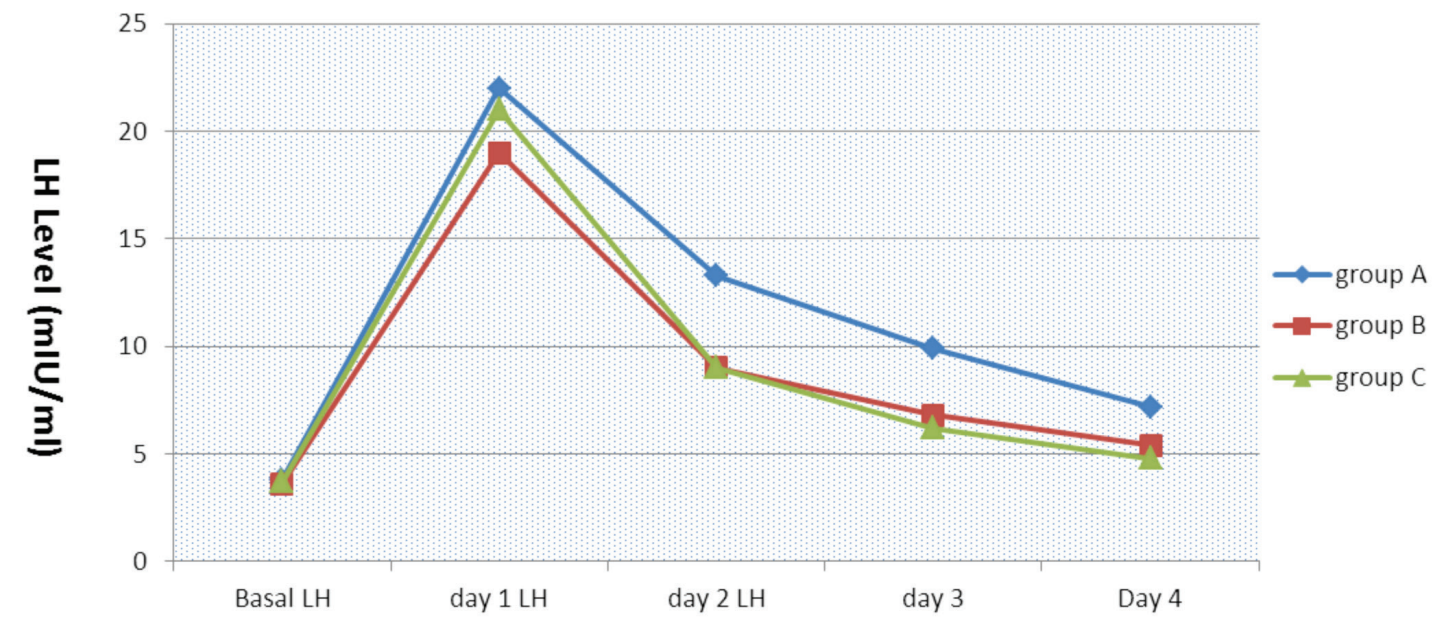


Table 3. Early changes in $\mathrm{E}_{2}$ level

\begin{tabular}{|c|c|c|c|c|}
\hline Group & \multirow{2}{*}{$\begin{array}{l}\text { Group A } \\
(N=34)\end{array}$} & \multirow{2}{*}{$\begin{array}{l}\text { Group B } \\
(N=34)\end{array}$} & \multirow{2}{*}{$\begin{array}{l}\text { Group C } \\
(N=23)\end{array}$} & \multirow[t]{2}{*}{ P Value } \\
\hline$E_{2}$ level $(\mathrm{Pg} / \mathrm{mI})$ & & & & \\
\hline Basal $E_{2}$ & $49 \pm 3.1$ & $49 \pm 3$ & $55 \pm 6$ & NS \\
\hline Day $2 \mathrm{E}_{2}$ & $139 \pm 12$ & $111 \pm 10$ & $115 \pm 6$ & NS \\
\hline Day $3 \mathrm{E}_{2}$ & $163 \pm 16$ & $130 \pm 14$ & $141 \pm 17$ & NS \\
\hline Day $4 E_{2}$ & $289 \pm 34$ & $212 \pm 29$ & $227 \pm 31$ & NS \\
\hline Day $5 \mathrm{E}_{2}$ & $441 \pm 55$ & $332 \pm 44$ & $324 \pm 50$ & NS \\
\hline
\end{tabular}

Figure 2. Early changes in $\mathrm{E}_{2}$ level

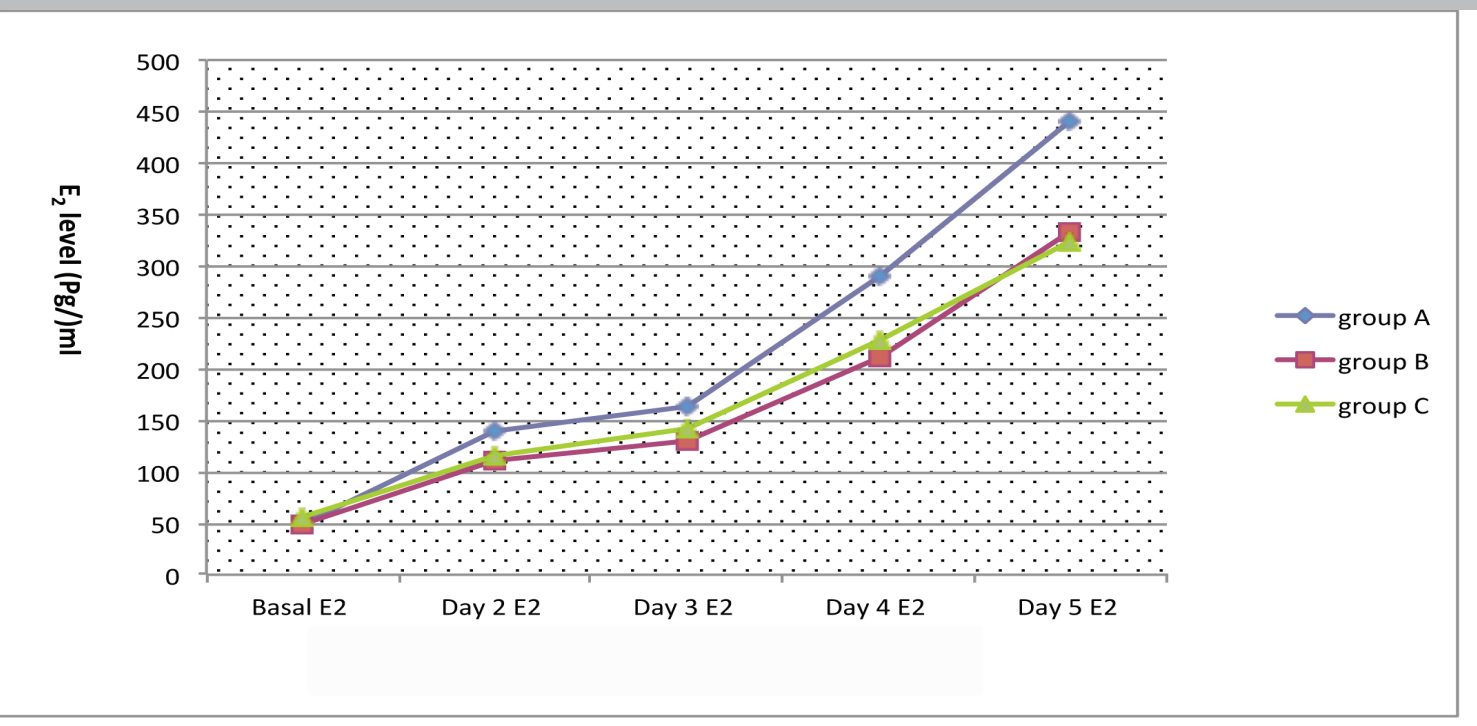

\section{Figure 3. Late changes in LH levels}

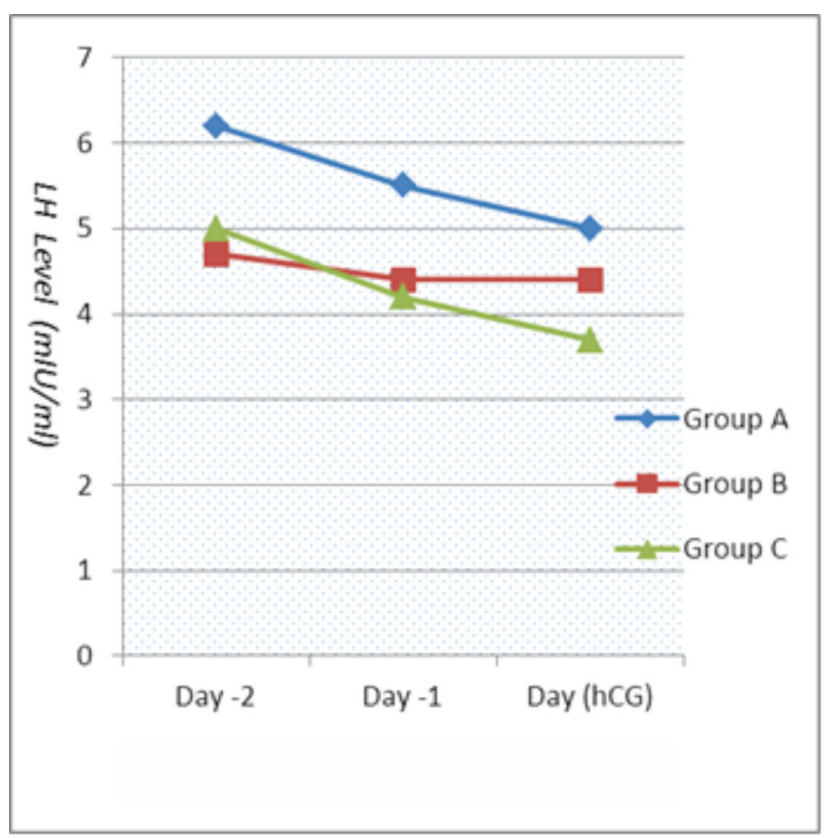

Figure 4. Late changes in $\mathrm{E}_{2}$ levels

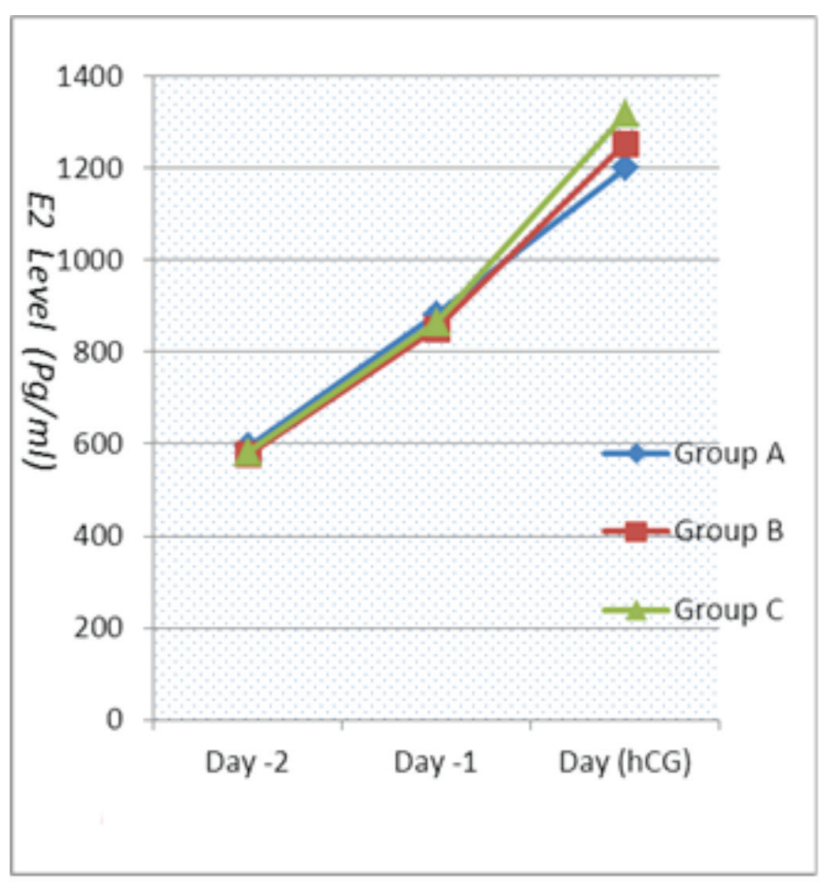


Table 4. Late hormonal changes

\begin{tabular}{|c|c|c|c|c|}
\hline Group & \multirow{2}{*}{$\begin{array}{l}\text { Group A } \\
(N=34)\end{array}$} & \multirow{2}{*}{$\begin{array}{l}\text { Group B } \\
(N=34)\end{array}$} & \multirow{2}{*}{$\begin{array}{l}\text { Group C } \\
(N=23)\end{array}$} & \multirow[t]{2}{*}{ P Value } \\
\hline Hormonal level & & & & \\
\hline Day -2 LH level (mIU/ml) & $6.2 \pm 0.6$ & $4.7 \pm 0.4$ & $5 \pm 0.7$ & NS \\
\hline Day -1 LH level (mIU/ml) & $5.5 \pm 0.3$ & $4.4 \pm 0.3$ & $4.2 \pm 0.5$ & NS \\
\hline Day (hCG) LH level (mIU/ml) & $5 \pm 0.3$ & $4.4 \pm 0.3$ & $3.7 \pm 0.4$ & NS \\
\hline Day -2 $\mathrm{E}_{2}$ level $(\mathrm{Pg} / \mathrm{mI})$ & $593 \pm 36$ & $577 \pm 38$ & $581 \pm 102$ & NS \\
\hline Day -1 $\mathrm{E}_{2}$ level $(\mathrm{Pg} / \mathrm{ml})$ & $882 \pm 61$ & $851 \pm 66$ & $865 \pm 150$ & NS \\
\hline Day (hCG) $E_{2}$ level $(P g / m l)$ & $1200 \pm 89$ & $1253 \pm 94$ & $1317 \pm 285$ & \\
\hline
\end{tabular}

Table 5. Stimulation requirements and outcome

\begin{tabular}{|c|c|c|c|c|}
\hline Group & Group A $(\mathbf{N}=34)$ & Group B $(N=34)$ & Group C $(N=23)$ & P Value \\
\hline Retrieval cycles & 31 & 31 & 21 & NS \\
\hline Cancellation & 3 & 3 & 2 & NS \\
\hline Days of stimulation & $7.25 \pm 0.3$ & $7.7 \pm 0.3$ & $7.5 \pm 0.5$ & NS \\
\hline Number of ampules & $14.5 \pm 0.6$ & $15.4 \pm 0.6$ & $15 \pm 1$ & NS \\
\hline Metaphase 2 oocytes & $10 \pm 0.8$ & $11 \pm 0.8$ & $9.5 \pm 1.17$ & NS \\
\hline Immature oocytes & $1.3 \pm 0.2$ & $1.2 \pm 0.25$ & $1 \pm 0.2$ & NS \\
\hline Metaphase 2 oocytes & $6.7 \pm 0.7$ & $8 \pm 0.7$ & $7.4 \pm 1.1$ & NS \\
\hline Embryos & $3.2 \pm 0.5^{*}$ & $4.6 \pm 0.5^{*}$ & $3.5 \pm 0.6$ & NS \\
\hline Pregnancy & 12 & 12 & 8 & \\
\hline Pregnancy Per cycle (\%) & 35.3 & 35.3 & 34.8 & NS \\
\hline
\end{tabular}

$55 \pm 6 \mathrm{Pg} / \mathrm{ml}$ ) were similar in the 3 groups. The level of $E_{2}$ rose markedly on the second day of stimulation to a mean of $139 \pm 12 \mathrm{Pg} / \mathrm{ml}, 111 \pm 10 \mathrm{Pg} / \mathrm{ml}$ and $115 \pm 12 \mathrm{Pg} / \mathrm{ml}$ in groups $A, B$ and $C$ respectively and kept rising on the days after. These values did not differ significantly between the three groups. (Table 3, Figure 2)

\section{Late hormonal changes:}

All the three doses of the agonist were sufficient to suppress LH and prevent its spontaneous surge. The mean level of LH on the day of hCG administration was $5 \pm 0.3 \mathrm{mIU} / \mathrm{ml}, 4.4 \pm 0.3 \mathrm{mIU} / \mathrm{ml}$ and $3.7 \pm 0.4 \mathrm{mIU} /$ $\mathrm{ml}$ in groups $\mathrm{A}, \mathrm{B}$ and $\mathrm{C}$ respectively. These values did not differ significantly from those of the preceding 2 days and between the three groups (Table 4, Figure 3,4)

\section{Stimulation requirements and outcome:}

The stimulation requirements in the form of days of stimulation $(7.25 \pm 0.3,7.7 \pm 0.3$ and $7.5 \pm 0.50)$ or the total number of ampoules of gonadotropins $(14.5 \pm 0.6,15.4 \pm 0.6$ and $15 \pm 1)$ did not differ between the three groups. The mean number of follicles aspirated $(10 \pm 0.8,11 \pm 0.8$ and $9.5 \pm 1.1)$ and the mean number of Metaphase 2 oocytes retrieved (6.7 \pm 0.7 , $8 \pm 0.7$ and $7.4 \pm 1.1$ ) were similar in the three groups. The rates of fertilization and cleavage were similar in the three groups. The mean number of embryos available for transfer was $6.4 \pm 0.5,9.4 \pm 0.5$ and $7 \pm 0.7$ in groups $A, B$ and $C$, respectively; with a significant difference only between groups $\mathrm{A}$ and $\mathrm{B}$. Pregnancy rates per cycle were $35.3 \%, 35.3 \%$ and $34.8 \%$ for groups $A, B$ and $C$, respectively; with no significant difference. (Table 5)

\section{DISCUSSION}

Controlled ovarian stimulation for assisted reproduction uses gonadotropin releasing hormone agonist (GnRH-a) routinely, either in its short (flare-up) or long protocol. The main benefit achieved by GnRH agonist use is the prevention of spontaneous $\mathrm{LH}$ surge leading to cycle cancellation (Broekmans et al., 1996). Such a benefit explains why a marked improvement of IVF results was associated with the introduction of the agonist use. LH surges occur in $20 \%$ of IVF patients leading to cancellation of the IVF cycles as shown in placebo-controlled studies of GnRH agonists (Janssens et al., 2000; Edwards et al., 1996).

Many studies have investigated the optimal dose of GnRH-a since the early 1980s (Tolis et al., 1982; Monroe et al., 2006). The routine daily dose of the different agonists was introduced by trials and is still not uniformly established. The adopted daily dose of triptorelin, for multifollicular ovarian stimulation (MFOS) has been $100 \mathrm{mg}$. Due to the slower and lower ovarian response after complete desensitization of the pituitary (especially in poor responders), several authors have suggested that the $\mathrm{GnRH}$-a dose reduction of should be possible (Ben-Rafael et al., 2000; Janssens et al., 1998; 2000; Broekmans et al., 1996).

It has been shown that once the pituitary gland has been suppressed, the $\mathrm{GnRH}$-a dose required to prevent the LH surge decreases with the length of treatment (Sandow \& Donnez, 1990). Reducing the daily administered dose of GnRH-a for MFOS has been successful in poor responders, without having a detrimental effect on the ovarian response to stimulation (Takeuchi et al., 2001; Yakin et al., 2001). However, a comparative study has reported the cancellation rate to be significantly higher without a favourable pregnancy rate in those receiving a microdose in the GnRH-a protocol (Leondires et al., 1999).

Among the advantages of reducing the dose of the agonist are decreasing the cost and side effects of the medications, decreasing the amount of gonadotropins used for 
stimulation with its costs and the possible occurrence of ovarian hyperstimulation. We have to weigh these advantages against the possible insufficiency of the smaller dose to maintain suppression of the pituitary gland and to prevent the occurrence of the spontaneous LH surge leading to cycle cancellation.

Simon et al. (1994) compared a continuous fixed dose of $0.5 \mathrm{mg}$ triptorelin to tapering the dose; from a starting dose of $0.5 \mathrm{mg}$ to a dose of $0.1 \mathrm{mg}$ after achieving down regulation. They reported this method manages to reduce the total dose of GnRH-a without any adverse effects on ovarian response or clinical results. In another trial, Elgendy and co-workers reported that more oocytes were retrieved and more embryos were obtained with intranasal nafarelin $200 \mathrm{mg}$ three times daily followed by a reduction to twice the daily dose after down regulation, versus continuous $200 \mathrm{mg}$ three times daily until the hCG day (Elgendy et al., 1998).

In a study by Dal Prato and associates, partial desensitization with reduced $\mathrm{GnRH}-\mathrm{a}$ dose was superior to the long-acting depot form (Dal Prato et al., 2001). Desensitization using $100 \mathrm{mg}$ triptorelin followed by $50 \mathrm{mg}$ significantly reduced the duration of MFOS and gonadotropin doses compared with the group on 3.75 mg depot triptorelin. In another more recent study by Ellenbogen, et al. (2006), 106 IVF patients were divided into 2 groups comparing single half dose of triptorelin to its full dose. The authors concluded that half the dose offers a useful alternative for pituitary gland suppression in IVF patients, improving treatment outcome. It also reduces cost and undesirable side effects of the GnRH-a (Ellenbogen et al., 2006).

The clinical efficacy of the $100 \mathrm{mg}$ dose of triptorelin was suggested by Janssens and his team in their two dose-finding studies. They found that 15, 50 and 100 mg were effective doses that induced adequate desensitization (Janssens et al., 2000), and that more oocytes and embryos were obtained with 50 and $100 \mathrm{mg}$ compared with $15 \mathrm{mg}$ or placebo7, in women with idiopathic, tubal, or male factor infertility with basal FSH levels of $\leq 10 \mathrm{mIU} / \mathrm{ml}$.

If the reduced dose of the agonist used in long protocols were successful in avoiding spontaneous LH surge, as shown in most of the above mentioned studies, this advantage will apply also to the short protocol.

An earlier report addressed another aspect of $\mathrm{GnRH}-\mathrm{a}$ dose reduction and warned of the possible occurrence of ovarian hyperstimulation, even when using sub therapeutic doses of GnRH-a (Navot et al., 1991). This possibility however, may not apply to those who are poor or low responders, where a reduced $\mathrm{GnRH}-\mathrm{a}$ dose may avoid profound pituitary suppression and improve ovarian responsiveness to gonadotropin.

Based on these experiences, the objective of this prospective randomized controlled study was to characterize the daily changes in the levels of luteinizing hormone (LH) and estradiol $\left(E_{2}\right)$ and to compare the intracytoplasmic sperm injection (ICSI) outcome with 3 different doses of GnRH-a (Triptorelin, $0.1 \mathrm{mg}, 50 \mu \mathrm{g}$, and $25 \mu \mathrm{g}$ ) used in a short protocol for normal ovulatory females. The three study groups were similar regarding their age and contributing factors of infertility and its duration. They also started with the same dose of gonadotropins used for stimulation to avoid any bias that may result from variation in the characteristics of patients or treatment regimens. Such variations are well known to affect the results of ART cycles.

It was expected that the use of smaller dose of the agonist would decrease the dose of gonadotropins used, as suggested by some studies (Dal Prato et al., 2001). But this was not shown in this study, as stimulation requirements in the form of the number of ampoules of gonadotropins and the days of stimulation required to reach the criteria of hCG administration were comparable in the three groups. The difference between the three doses may be less than required to produce this effect.

The administration of $\mathrm{GnRH}$ agonist during the early follicular phase results in a flare of both FSH and LH for the following 3 to 5 days before the down regulation phenomenon takes place. This study showed that the three doses of the agonist used were capable of producing such a flare in $\mathrm{LH}$, which reached a peak 24 hours after initiation of therapy and showed a sharp drop on the second day, fading away after 4-5 days. Similar duration of this flare up was recorded in other studies (Navot et al., 1991; Lemay et al.,1984). The significance of such an occurrence in gonadotropins induced by the agonist is still controversial, and whether it is detrimental or beneficial to the follicular development is not settled. Some studies reported it as being useful and stimulating to the recruitment of a higher number of follicles (Surrey et al.,1998), while others stressed on the possible association between high LH level and follicular atresia (Polan et al.,1986; Shima et al.,1987). In the current study, the three doses of the agonist were sufficiently potent to produce a flare of $\mathrm{LH}$ and $\mathrm{E}_{2}$ level. Although the magnitude and duration of this flare seems to be related to the dose of the agonist used, we did not find any significant effect of this variation on the final IVF outcome.

The most meaningful statistics of IVF is the number of live birth per number of initiated cycles. It was recognized before commencing this study that the sample size would not provide sufficient power to test the possible difference, if any, in the pregnancy rate between the three groups.

\section{CONCLUSION}

- The three doses of the agonist were sufficiently potent to produce a flare of $\mathrm{LH}$ and $\mathrm{E}_{2}$, although the magnitude and duration of this flare seems to be related to the dose of the agonist used. We did not find any significant effect of this variation on the final IVF outcome The three doses of the agonist were sufficiently potent to avoid spontaneous LH surge and to block the pituitary response to the rising estradiol level.

- Stimulation requirements, such as the number of ampoules of gonadotropins and the days of stimulation required to reach the criteria of hCG administration were comparable in the three groups

- The dose of $50 \mu \mathrm{g}$ Triptorelin per day yielded a higher number of follicles and embryos, but this difference did not reach statistical significance and did not reflect on the final outcome in terms of pregnancy rates.

- Based on the similarity in the stimulation requirements and final outcome of the three doses of the agonist used, treatment cost would be the most important factor to consider.

\section{Acknowledgements}

The authors would like to thank Dr. Marta Susana Gallego for her invaluable support.

\section{CONFLICT OF INTERESTS}

No conflict of interest have been declared.

\section{Corresponding author:}

Abdulmagid Sarhan

Professor, Zagazig University, Egypt

E-mail: Sarhan_a@hotmail.com

\section{REFERENCES}

Ben-Rafael Z, Lipitz S, Bider D, Mashiach S. Ovarian hyporesponsiveness in combined gonadotropin-releasing hor- 
mone-agonist and menotropin therapy is associated with low serum follicle-stimulating hormone levels. Fertil Steril $1991 ; 55: 272-5$.

Broekmans FJ, Hompes PGA, Lambalk CB, Schoute E, Broeders A, Schoemaker J. Short term pituitary desensitization: effects of different doses of the gonadotrophin-releasing hormone agonist triptorelin. Hum Reprod 1996;11:55-60.

Dal Prato L, Borini A, Trevisi MR, Bonu MA, Sereni $E$, Flamigni $C$. Effect of reduced dose of triptorelin at the start of ovarian stimulation on the outcome of IVF: a randomized study. Hum Reprod 2001;16:1409-14.

Edwards RG, Lobo R, Bouchard P. Time to revolutionize ovarian stimulation. Hum Reprod. 1996; 11:917-9.

Elgendy $M$, Afnan $M$, Holder $R$, Lashen $H$, Afifi $Y$, LentonW, Sharif $K$. Reducing the dose of gonadotrophin hormone agonist on starting ovarian stimulation: effect in ovarian response and in-vitro fertilization outcome. Hum Reprod 1998;13:2382-5.

Ellenbogen A, Gidoni Y, Rotfarb N, Michaeli M. Comparison of a single half-dose, long acting form of gonadotropin releasing hormone analog (GnRH-a) and a full dose of $\mathrm{GnRH}-\mathrm{a}$ for pituitary suppresion in an vitro fertilization program. Ferti Steril. 2006; 86: S416.

Janssens RMJ, Vermeiden JPW, Lambalk CB, Schats R, Schoemaker J. Gonadotropin-releasing hormone agonist dose dependency of pituitary desensitization during controlled ovarian hyperstimulation in IVF. Hum Reprod 1998; 13: 2386-91.

Janssens RMJ, Lambalk CB, Vermeiden JPW, Schats R,Bernards JM, Rekers-Mombarg LT, Schoemaker J. Dose finding study of triptorelin acetate for prevention of a premature LH surge in IVF: a prospective, randomized, double-blind, placebo-controlled study. Hum Reprod. 2000; 15:2333-40.

Lemay A, Maheux R, Faure N, Jean C, Fazekas A. Reversible hypogonadism by luteinizing hormone releasing hormone (LH-RH) agonist (Buserelin) as a new therapeutic approach for endometriosis. Fertile Steril 1984;41:863-71.

Lenton E, Mohamed K. Optimizing assisted reproduction: impact of low-dose gonadotropin-releasing hormone agonist on in vitro fertilization outcome. Fertil Steril. 2005;84:1783-5.

Leondires MP, Escalpes M, Segars JH, Scott RT Jr, Miller BT. Microdose follicular phase gonadotropin-releasing hormone agonists(GnRH-a) compared with luteal phase $\mathrm{GnRH}-\mathrm{a}$ for ovarian stimulation at in vitro fertilization. Fertil Steril. 1999;72:1018-23.

Monroe SE, Blumenfeld $\mathrm{Z}$, Andreyko JL, Schriock E, Henzl MR, Jaffe RB. Dose-dependent inhibition of pituitary-ovarian function during administration of a go- nadotropin-releasing hormone agonistic analog (nafarelin). J Clin Endocrinol Metab 1986;63:1334-41.

Navot D, Rosenwaks Z, Anderson F, Hodgen GD. Gonadotropin-releasing hormone agonist-induced ovarian hyperstimulation: low-dose side effects in women and monkeys. Fertil Steril 1991;55:1069-75.

Orvieto R, Kerner R, Krissi H, Ashkenazi J, Ben Rafael Z, Bar-Hava I. Comparison of leuprolide acetate and triptorelin in assisted reproductive technology cycles: a prospective, randomized study. Fertil Steril. 2002;78:1268-71.

Polan ML, Danielle A, Russel JB, De Cherney AH. Ovulation induction with human menopausal gonadotropin compared to human urinary follicle-stimulating hormone results in a significant shift in follicular fluid androgen levels without discernible differences in granulosa-luteal cell function. J Clin Endocrinol Metab. 1986;63: 1284-91.

Sandow J, Donnez J. Clinical pharmacokinetics of LHRH analogues. In: Brosens I, Jacob HS, Runnenbaum B, eds. LHRH analogues in gynaecology. Lancashire: Parthenon Publishing; 1990. pp 17-31.

Shima K, Kitayama S, Nakano R. Gonadotropins binding sites in human ovarian follicles and corpora lutea during the menstrual cycle. Obstet Gynecol. 1987;69:809-6.

Simon A, Benshushan A, Shushan A, Zajicek G, Dorembus $D$, Lewin A, Laufer N. A comparison between a standard and reduced dose of D-Trp-6-luteinizing hormone-releasing hormone administered after pituitary suppression for in-vitro fertilization. Hum Reprod 1994;9:1813-7.

Surrey ES, Bower J, Hill DM, Ramsey J, Surrey MW. Clinical and endocrine effects of a microdose GnRH agonist flare regimen administered to poor responders who are undergoing in vitro fertilization. Fertil Steril. 1998;69:419-24.

Takeuchi S, Minoura H, Shibahara T, Tsuiki Y, Noritaka F, Toyoda N. A prospective randomized comparison of routine buserelin acetate and a decreasing dosage of nafarelin acetate with a low-dose gonadotropin-releasing hormone agonist protocol for in vitro fertilization and intracytoplasmic sperm injection. Fertil Steril 2001;76:532-7.

Tolis G, Ackman D, Stellos A, Mehta A, Labrie F, Fazekas AT, Comaru-Schally AM, Schally AV. Tumor growth inhibition in patients with prostatic carcinoma treated with luteinizing hormone-releasing hormone agonists. Proc Natl Acad Sci USA 1982;79:1658-62.

Yakin K, Kahraman,S, Vanlioglu F, , Kumtepe Y. Comparison of microdose and standard doses of GnRH analogue in flare protocols for controlled ovarian hyperstimulation in poor responders. Fertil Steril. 2001; 76:S223. 